\title{
The linen factory park of "Biysk linen company OAO " (open joint-stock company) landscape gardening redesign project in Biysk city
}

\author{
N.A. Shenmayer, M.M. Litvinova, V.V. Konyukhova, S. S. Romanova \\ Reshetnev Siberian State University of Science and Technology, Krasnoyarsky Rabochy Av., 31, \\ 660037 Krasnoyarsk, Russia
}

\begin{abstract}
The aim of this research is to develop more rational proposal to improve the green area on the territory of Biysk city park in terms of its recreation, protective, sanitary and hygienic, aesthetic and research purposes. The inventory of green plantations was carried out according to the method of V.S. Theodoronsky, I.O. Bogovaya by enumeration survey of growing stand on the park area. The inventory results of green areas and the assessment of green plantations health are shown in this work, the landuse planning and landscape gardening compliance of the area were examined too. According to the results of the study, the causes are established and the methods are set for the green plantations redesign of the park area. The list of arboreal and herbaceous plants and landscape design solutions were chosen by taking into account the environmental conditions of the Altai Territory.
\end{abstract}

\section{Introduction}

A modern city, regardless of its size and location, has industrial zones. Green spaces in these zones are designed to optimize the microclimate, increase the sanitizing effect and improve the urban environment from the effects of emissions. For industrial landscaping, the compositional relationship with the external environment is of great importance, which is determined by the functional purpose and location in urban development. The development of landscaping and landscaping projects in special-purpose territories should take into account the general situation, the volume of emissions from the enterprise, and the degree of their impact on human health. The creation of plantings on the territories of industrial enterprises is one of the main measures for their improvement and, consequently, for improving the working conditions of workers and employees of enterprises [1].

Greening of industrial enterprises is aimed at: reducing the impact of harmful emissions (dust, gases, etc.) on employees in the enterprise; improving the environment by equalizing the temperature and humidity of the air, protecting against the effects of winds, etc.; creating comfortable places for short-term outdoor recreation for employees; reducing the surface area and enriching the overall appearance of the enterprise territory [2].

The purpose of the research is to develop a more rational proposal to improve the situation with green spaces in the Biysk park in terms of recreational, protective, sanitary, aesthetic and research functions. 
To achieve this goal, the following tasks are set: research of the reconstruction object, analysis, development of recommendations for eliminating negative phenomena in the existing green spaces, as well as creating the most favorable landscape organization in the Biysk park.

\section{Methods and types of the Earth's remote sensing}

The object of the study was the park, which belongs to JSC "Biysk Linen Company", located in the Altai Territory in the city of Biysk. The linen company produces and sells: short and long linen fiber of various numbers, linen yarn for the production of tarpaulins and technical fabrics; linen yarn for carpet production; linen twine, etc. The area of the park located next to the flax plant is 2.8 hectares. The territory of the plant is separated from the park by a fence made of concrete slabs with a height of $3 \mathrm{~m}$.

The inventory of green plantings was carried out according to the method of V. S. Teodoronsky, I. O. Bogova $[3,4]$ by a continuous list of plantings available on the object and assigning them an individual inventory number, as well as determining plant species and their biometric indicators.

\section{Analysis of the main ERS data sources for the DEM development}

Analyzing the data, we can conclude that the overall condition of green spaces is satisfactory. The range of plantings growing in the park is represented by such species as: rough elm (Ulmus glabra Huds.), common pine (Pinus sylvestris L.), hanging birch (Betula pendula Roth), felt cherry (Cerasus tomentosa (Thunb.) Wall.), balsamic poplar (Populus balsamifera L.), white willow (Salix alba L.), ash maple (Acer negundo L.), Siberian spruce (Picea obovata Ledeb.), gray spiraea (Spiraea $\times$ cinerea), wrinkled rose (Rosa rugosa Thunb.).

A partial reconstruction is planned. In total, 55 specimens of wood species are subject to removal: ash maple (Acer negundo L.) 14 pcs., Scots pine (Pinus sylvestris L.) - 21 pcs., hanging birch (Betula pendula Roth) - 1 pc. and wrinkled rose (Rosa rugosa Thunb.) - 19 pcs. The main reasons for the removal of plantings are non-compliance with the norms and rules of landscaping of the park next to the industrial enterprise.

The territory of the park was divided into four functional zones: quiet recreation, cultural and entertainment and children's recreation. In the quiet recreation area along the path, a hedge of brilliant dogwood (Cotoneaster lucidus Schlecht.) is designed. Plantings of rough elm (Ulmus glabra Huds.) are recommended to carry out sanitary pruning, remove withered and wind-broken branches. The road and path network is an asphalt surface with a width of $5 \mathrm{~m}$.

From the existing plantings on this site grow such plants as: hanging birch (Betula pendula Roth) in the amount of 11 pcs., white willow (Salix alba L.) - 1 pc., Siberian spruce (Picea obovata Ledeb.) - 1 pc., ash maple (Acer negundo L.) - 4 pcs., common pine (Pinus sylvestris L.) - 1 pc., balsamic poplar (Populus balsamifera L.) - 3 pcs. Trees and shrubs will be planted to the above trees: berry apple (Malus baccata (L.) Borkh.) - 4 pcs., Siberian mountain ash (Sorbus sibirica Hedl.) - 2 pcs., Hungarian lilac (Syringa josikaea Jacg. fil.) 3 pcs., pinnate hawthorn (Crataegus pinnatifida Bge.) - 2 pcs., Spiraea vangutta (Spiraea $\times$ vanhoutei) - 1 pc., Manchurian walnut (Juglans mandshurica Maxim.) - 1 pc., Ussurian pear (Pyrus ussuriensis Maxim.) - 1 pc., Thunberg barberry (Berberis thunbergii) - 1 pc. 1 piece, round - leaved irga (Amelanchier ovalis Med.)-1 piece for creating decorative tree and shrub groups. 
It is also recommended to install gazebos on the site for visitors to relax. They will be accessed by concrete slab paths to maintain a unified style of the park.

The cultural and entertainment area is located closer to the river, in the eastern part of the territory. Along the paths, a hedge of brilliant dogwood (Cotoneaster lucidus Schlecht.) is also designed. Of the existing plantings, there are: balsamic poplar (Populus balsamifera L.) - 6 pcs., common pine (Pinus sylvestris L.) - 4 pcs., Siberian spruce (Picea obovata Ledeb.) -3 pcs., hanging birch (Betula pendula Roth) - 3 pcs., ash maple (Acer negundo L.) - 6 pcs., two white willows (Salix alba L.) and two wrinkled roses (Rosa rugosa Thunb.). It is recommended to plant on this site one copy of Siberian mountain ash (Sorbus sibirica Hedl.), Virgin cherry (Padus virginiana (L.) Mill.), berry apple (Malus baccata (L.) Borkh.), gray spiraea (Spiraea $\times$ cinerea), Thunberg barberry (Berberis thunbergii) and two Cossack juniper (Juniperus Sabina). On the flowerbeds available on this site, we recommend planting: Astilbe chinensis 'Visions in Red', Astrantia major 'Moulin Rouge', hybrid vervain 'Etna' (Verbena hybrida hort. 'Etna'), creeping beetle 'Mahogany' (Ajuga reptans L. 'Mahogany'), ampelium ampelium 'Sapphire' (Lobelia pendula L. 'Saphir'), ampelium ampelium 'White Cascade' (Lobelia pendula L. 'Saphir'), Kamchatka stonecrop (Sedum kamtschaticum), milky-flowered peony 'Red Sarah Bernard' (Paeonia lactiflora 'Red Sarah Bernhardt'), Schmidt's wormwood 'Silver Mound' (Artemisia schmidtiana 'Silver Mound'), Phlox paniculata 'Early Purple Eye' (Phlox paniculata 'Early Purple Eye'), Hosta hybrida 'Golden Tiara' (Hosta hybrida 'Golden Tiara'), Thunberg's barberry (Berberis thunbergii). The benches are recommended to be repaired and painted. The fountain is proposed to be cleaned of debris and restored, and the finishing tiles replaced with new ones. It is also planned to restore the gazebo and replace the embankment fence. On this site there is a destroyed building, which is proposed to be dismantled and instead place a portable summer cafe in the form of a tent. Here, visitors to the park will be able to hide from the scorching sun, as well as buy cold drinks and ice cream [5].

The children's recreation area is located in the south-west of the territory. Here it is necessary to uproot old-growth tree and shrub vegetation. In the vacated territory, it is recommended to set up two playgrounds with a sand surface: one for children from 1 to 3 years old, the other - from 3 to 12 years old. On these sites, it is planned to install children's entertainment complexes, slides and sandboxes. The playgrounds will have benches for recreation and child care. The paths to the playgrounds are made with an asphalt surface for harmony with the rest of the park. Here are preserved such trees as: hanging birch (Betula pendula Roth) - 10 pcs., common pine (Pinus sylvestris L.) - 10 pcs., rough elm (Ulmus glabra Huds.) - 8 pcs., ash maple (Acer negundo L.) - 1 pc. To create a group, we plant 9 pieces of Hungarian lilac (Syringa josikaea Jacg. fil.) to the existing remaining plantings. To create shade on the playground, the existing plants are planted with berry apple (Malus baccata (L.) Borkh.) - 2 pcs. and Manchurian walnut (Juglans mandshurica Maxim.) - 2 pcs. It is recommended to create a group between the paths, near the playground, from the following tree and shrub vegetation: gray spiraea (Spiraea $\times$ cinerea) -2 pcs., Manchurian walnut (Juglans mandshurica Maxim.) - 1 pc., low almond (Prunus tenella Batsch) - 3 pcs., Hungarian lilac (Syringa josikaea Jacg. fil.) -2 pcs., Wangutta spiraea (Spiraea $x$ vanhouttei) -2 pcs., white turf (Swida alba L.) - 2 pcs. These plants are very decorative. The Manchurian nut (Juglans mandshurica Maxim.) is decorative in the shape of the crown, leaves, inflorescences, and fruits. The bark on young trunks is light gray, wrinkled, dark gray with age, almost black. Spiraea gray (Spiraea $\times$ cinerea) is decorative in the summer color of the leaves: dull green, lighter below, the autumn color of the leaves is yellow. The flowers are white, the petals are oblong-rounded, longer than the stamens. Inflorescences simple loose shields, densely covering the shoots. White turf (Swida alba L.) is decorative all year round: young shoots are bright coral-red, old wood is red - or olive-brown, with a beautiful bark pattern. The low almond (Prunus tenella Batsch) has a peak of decorative 
effect during the flowering period. Decorative properties: crown shape, color of shoots, leaves, flowers, fruits. It is for the spring abundant flowering that almonds are used in plantings on the site [6].

Further, groups are created using Siberian mountain ash (Sorbus sibirica Hedl.) - 2 pcs., white turf (Swida alba L.) - 5 pcs., mountain ash 'Sem' (Sorbaria sorbifolia (L.) 'Sem') - 2 pcs., Vangutta spiraea (Spiraea $\times$ vanhoutei) -4 pcs., gray spiraea (Spiraea $\times$ cinerea) -4 pcs., low almond (Prunus tenella Batsch) - 6 pcs., wrinkled rose (Rosa rugosa Thunb.) - 1 pc., Thunberg barberry (Berberis thunbergii) - 2 pcs., pinnate hawthorn (Crataegus pinnatifida Bge.) - 6 pcs., round-leaved irga (Amelanchier ovalis Med.) - 1 pc., virgin cherry (Padus virginiana (L.) Mill.) - 6 pcs., Manchurian nut (Juglans mandshurica Maxim.) - 1 pc., berry apple (Malus baccata (L.) Borkh.) - 4 pcs.

It is also recommended to install a gazebo on the site for a more private rest, in which guests of the park can admire groups of trees and shrubs, relax in the shade during the hot period of time. A concrete slab path will lead to the gazebo. A hedge of brilliant dogwood (Cotoneaster lucidus Schlecht.) along the path visually separates the playground from the volleyball court, which is located on the adjacent plot [7]. The sports and recreation area is located in the south-east of the territory. Here it is recommended, after leveling the soil, to install a volleyball court. The surface of the site is poured out of sand, since this is the territory of the embankment and sand covering is a more economical option. Existing plantings: rough elm (Ulmus glabra Huds.) - 7 pcs., hanging birch (Betula pendula Roth) 13 pcs., ash maple (Acer negundo L.) - 1 pc., Siberian spruce (Picea obovata Ledeb.) - 9 pcs. Siberian spruce (Picea obovata Ledeb.) is located on the edge of the bank and the root system does not allow the spruce to linger on the surface and the trees begin to fall into the river. To prevent the destruction of the shore, it is recommended to plant a white willow (Salix alba L.). To the existing plantings of rough elm (Ulmus glabra Huds.) and hanging birch (Betula pendula Roth), in addition, we plant one copy of Hungarian lilac (Syringa josikaea Jacg. fil.), Vangutta spiraea (Spiraea $\times$ vanhoutei), berry apple (Malus baccata (L.) Borkh.), white turf (Swida alba L.). To the east, to the group of existing common pines (Pinus sylvestris L.) and hanging birch (Betula pendula Roth), we add round-leaved irga (Amelanchier ovalis Med.) (1 pc.), pinnate hawthorn (Crataegus pinnatifida Bge.) (2 pcs.), Vangutta spiraea (Spiraea $\times$ vanhoutei) $(1$ pc.), white turf (Swida alba L.) $(2$ pcs.), Thunberg's barberry (Berberis thunbergii) $(1 \mathrm{pc}$.), gray spiraea (Spiraea $\times$ cinerea) $(1 \mathrm{pc}$.$) .$ A concrete flagstone path leads to the volleyball court. Next, a tree-shrub group of Virgin cherry (Padus virginiana (L.) Mill.), berry apple (Malus baccata (L.) Borkh.), Manchurian walnut (Juglans mandshurica Maxim.), Siberian mountain ash (Sorbus sibirica Hedl.) and two white derricks (Swida alba L.), Spiraea vangutta (Spiraea $\times$ vanhoutei), Spiraea gray (Spiraea $\times$ cinerea). Along the volleyball court, a row of four Ussurian pears (Pyrus ussuriensis Maxim.) is planted. Here, a gazebo made of wood will also look good, to which the same "floating" path made of concrete passes. On both sides of the path grow groups of berry apple (Malus baccata (L.) Borkh.), pinnate hawthorn (Crataegus pinnatifida Bge.) (2 pcs.), Vangutta spiraea (Spiraea $\times$ vanhoutei) $(2$ pcs.), Thunberg barberry (Berberis thunbergii), low almond (Prunus tenella Batsch) (2 pcs.), round-leaved irga (Amelanchier ovalis Med.), gray spiraea (Spiraea $\times$ cinerea). To the west, we design a group of Cossack junipers (Juniperus Sabina) (2 copies), Siberian spruce (Picea obovata Ledeb.), pinnate hawthorn (Crataegus pinnatifida Bge.), virgin cherry (Padus virginiana (L.) Mill.), roundleaved irga (Amelanchier ovalis Med.). To the south is a $3 \mathrm{~m}$ wide path with benches along it. This part of the park is home to such woody and shrubby plants as hanging birch (Betula pendula Roth) and Siberian spruce (Picea obovata Ledeb.). To them, we plant Cossack juniper (Juniperus Sabina) (2 pcs.), berry apple (Malus baccata (L.) Borkh.), Thunberg barberry (Berberis thunbergii), Virgin cherry (Padus virginiana (L.) Mill.) (3 pcs.), 
mountain ash 'Sem' (Sorbaria sorbifolia (L.) 'Sem'), round-leaved irga (Amelanchier ovalis Med.), pinnate hawthorn (Crataegus pinnatifida Bge.) (3 pcs.).

Along the path there is a group of tree and shrub vegetation to distinguish the path from the gazebo. The following species are used here: berry apple (Malus baccata (L.) Borkh.) 1 pc., virgin cherry (Padus virginiana (L.) Mill.) - 1 pc., Manchurian walnut (Juglans mandshurica Maxim.) - 1 pc., Siberian mountain ash (Sorbus sibirica Hedl.) - 1 pc., white turf (Swida alba L.) -2 pcs., Spiraea Vangutta (Spiraea $\times$ vanhouttei) -2 pcs., gray spiraea (Spiraea $\times$ cinerea) -2 pcs., Thunberg's barberry (Berberis thunbergii) -1 pc.

To create a group near the gazebo, the following plants are used: Ussuri pear-1 piece., round-leaved irga-1 piece., gray spiraea (Spiraea $\times$ cinerea) -1 piece., Vangutta spiraea (Spiraea $\times$ vanhoutei) -1 piece., Thunberg barberry (Berberis thunbergii) -1 piece., low almond (Prunus tenella Batsch) - 1 piece.

On the opposite side there is a group of apple trees (Malus baccata (L.) Borkh.) - 1 pc., Thunberg barberry (Berberis thunbergii) - 1 pc., pinnate hawthorn (Crataegus pinnatifida Bge.) - 1 pc., low almonds (Prunus tenella Batsch) - 1 pc., Vangutta spiraea (Spiraea $\times$ vanhoutei) - 1 pc. These groups create a secluded place for the gazebo. The gazebo is designed for relaxing in the shade and privacy of a person with nature [8].

To the east are four abandoned flower beds, overgrown with lawn grasses, on which well-groomed flower beds with their own decorative features will be created. The following plants will take part in the flower gardens: Chinese astilba "Vision in Red", large astrantia "Moulin Rouge", hybrid verbena "Etna", creeping creeper "Mahogany", ampelium ampelium "Sapphire", ampelium ampelium "White Cascade", Kamchatka ochitok, milkflowered peony "Red Sarah Bernhardt", Schmidt wormwood "Silver Mound", panicle phlox "Early Purple Eye", hosta hybrid "Golden Tiara", Thunberg's barberry, Japanese spirea.

Landscaping and landscaping activities will change the balance of the object's territory, which shows the ratio of planning elements and the spatial structure of the object (Table 1).

Table 1. Balance of the territory after reconstruction

\begin{tabular}{|c|c|c|c|}
\hline \multirow{2}{*}{ Name of elements } & \multicolumn{2}{|c|}{ Occupied area } & \multirow{2}{*}{$\begin{array}{c}\text { Number of plants, } \\
\text { pcs. }\end{array}$} \\
\cline { 2 - 3 } $\mathrm{m}^{2}$ & $\%$ & \\
\hline Tracks of the site & 5685,32 & 20 & \\
\hline $\begin{array}{c}\text { Area of green space, } \\
\text { total } \\
\text { including: } \\
\text { trees }\end{array}$ & 22505,78 & 80 & \\
shrubs & 2051,30 & 7 & \\
lawns & 7255,61 & 26 & $2104+808=2912$ \\
flower beds & 12811,87 & 45 & \\
\hline Total & 28197,00 & 2 & \\
\hline
\end{tabular}

\section{Conclusions}

The data in Table 1 show that after the reconstruction, the density of plantings in the park is $80 \%$. Thus, the density of trees is 71 pcs. per 1 ha (198 pcs. per 2.8 ha), with a normal 
planting density of up to 100 pcs. of trees per 1 ha. The number of shrubs per 1 ha was 1040 per 1 ha $(2912$ per 2.8 ha), with a normal shrub density of 1020 per 1 ha. The introduction of additional green spaces in the form of landscape groups, hedges, flower beds helps to increase the colorfulness of the landscape.

\section{References}

1. L.N. Blocka, Landscape ecological assessment of green space territories of limited use, 3 (2010)

2. I.J. Koropachinsky, Arboreal plants for landscape gardening of Krasnoyarsk (2014)

3. V.S. Theodoronsky, I.O. Bogovaya, Bogova Objects of landscape architecture. (2010)

4. V.S. Theodoronsky, G.P. Zherebtsov, The Planting of settlements. Urban planning basics (2010)

5. V.YU Konyuhov, A.M. Gladkih, I.I. Galyautdinov, Y.D. Severina, Economic aspects of green technologies (2019)

6. L. Gubacheva, A. Andreev, D. Shevchenko, I. Makarova, S. Andreev, Prospects for the development of green technologies for producing alternative energy resources (2019)

7. I.A. Bachurinskaya, N.V. Vasileva, M.N. Yudenko, S.A. Nikolikhina, "Green" technologies in housing: the experience of Russia, 4 (2020)

8. V.A. Chernyaeva, D.H. Wang, Green way: Engineering transformations to the green industrial technologies, 1 (2020) 